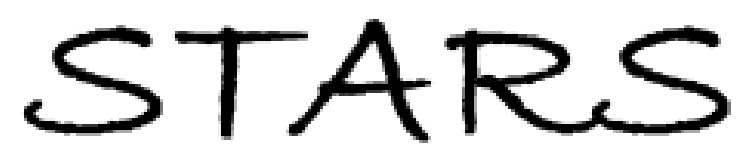

Rhetoric of Health \& Medicine

\title{
Book review: Rhetorical work in emergency medical services: Communicating in the unpredictable workplace
}

\author{
Marissa McKinley \\ Marissa.McKinley@quinnipiac.edu
}

Find similar works at: https://stars.library.ucf.edu/rhm

University of Central Florida Libraries http://library.ucf.edu

\section{Recommended Citation}

McKinley, Marissa (2020) "Book review: Rhetorical work in emergency medical services: Communicating in the unpredictable workplace," Rhetoric of Health \& Medicine: Vol. 3 : Iss. 1 , Article 2.

Available at: https://stars.library.ucf.edu/rhm/vol3/iss $1 / 2$

This Article is brought to you for free and open access by STARS. It has been accepted for inclusion in Rhetoric of Health \& Medicine by an authorized editor of STARS. For more information, please contact lee.dotson@ucf.edu.

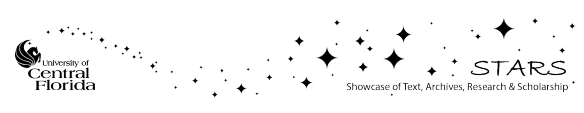


Book review: Rhetorical work in emergency medical services: Communicating in the unpredictable workplace

\section{Cover Page Footnote}

Recommended Citation: McKinley, M. (2020). A review of Rhetorical work in emergency medical services: Communicating in the unpredictable workplace [Supplemental material]. Rhetoric of Health \& Medicine, 3(1). doi:10.5744/rhm.2020.1006 


\section{A Review of Rhetorical Work in Emergency Medical Services: \\ Communicating in the Unpredictable Workplace}

\section{Marissa C. McKinley}

Rhetorical Work in Emergency Medical Services: Communicating in the Unpredictable Workplace. By Elizabeth L. Angeli. New York, NY: Routledge, 2019. 204 pages, $\$ 47.95$ paper, $\$ 23.98$ e-book.

\section{Elizabeth L. Angeli’s Rhetorical Work in Emergency Medical Services:}

Communicating in the Unpredictable Workplace details the rhetorical work undertaken by emergency medical services (EMS) professionals as they navigate the unstable nature of their workplace and respond to unpredictable medical situations. Angeli's main argument is that EMS professionals "harness rhetoric's power to navigate their highstakes, unpredictable workplace" (p. 13) through the use of verbal and nonverbal communication.

Before exemplifying the instability of the EMS workplace — not knowing "what to expect, what will happen, or where [to] go" (p. 18) —and before demonstrating the rhetorical work that EMS communicators undertake, Angeli uses the majority of chapter one to offer readers a "scene size-up" (p. 1). She explains that when EMS professionals are called to a scene, these personnel lean on their senses, memory, and intuition to gather and contextualize details about the scene and patient. The details gathered become the "backstory" for the emergency call and help warrant decisions surrounding patient treatment and documentation of the medical event (p. 1). Just as a "backstory" is used to justify the methods and processes enacted by EMS professionals, Angeli asserts that researchers, too, often have and rely upon a "backstory," or a "scene size-up," to help inform and contextualize their research design and findings (p. 1). The author states that 
it is in revealing a research project's backstory that readers can understand the exigencies for the project and how the researcher navigated any challenges, which may have shaped the outcomes for their research findings.

Angeli details her own "scene-size up" (p. 1) in chapter one, discussing how she became involved in EMS work and how she "managed, engaged with, and developed agency" while studying Lochville EMS (p. 2). The remainder of the chapter previews the discussions contained in each of the following six chapters. Chapters two through seven begin with narratives stemming from Angeli's own experiences working with EMS personnel and patients. These vignettes illustrate the primary argument contained in each chapter and begin to demonstrate EMS rhetorical work in action. The chapters conclude with "takeaways" for technical and professional communication (TPC) and rhetoric of health and medicine (RHM) readers and for EMS readers (p. 17).

To provide readers with a fuller understanding of the framework used to explain how EMS communicators use rhetoric in their workplace, chapter two, "Managing the Unpredictable Workplace through Rhetorical Work," further defines and explains the elements of rhetorical work. Chapter three, "A Rhetorical History of a Developing Field," captures the history and development of the EMS profession. Chapter four, "Studying the Unpredictable Workplace," describes the methods Angeli used to study the rhetorical work of Lochville EMS personnel. Chapter five, "Using Multisensory Invention in the Unpredictable Workplace," discusses how the EMS personnel Angeli studied engaged in the rhetorical work of "multisensory invention" (p. 87), defined as a "process through which EMS professionals gather data through the senses and use intuition to assess a 
situation, act, and communicate relevant information to different audiences" (p. 87). Multisensory invention is, as Angeli argues, a key component to rhetorical work in EMS. Informed by the theories of distributed cognition, multisensory invention, and rhetorical memory, chapter six, "Integrating Distributed Cognition, Memory, and Writing into the Unpredictable Workplace," demonstrates how EMS personnel use three types of memory - individual, collaborative, and professional - to "distribute cognition while composing to reduce cognitive workload" (p. 17). Finally, chapter seven, "Preparing Communicators for Unpredictable Workplaces," presents the pedagogical applications of Angeli's research findings before synthesizing them and offering activities that TPC, RHM, and EMS educators can assign to students and trainees to help them cultivate data gathering, decision-making, and documentation skills.

All of Angeli's intended audiences-EMS, TPC, and RHM researchers, teachers, and students - can find value in her text. For example, EMS readers will likely find value in the review of the profession's history and in the stories that emerge out of the workplace. While the review highlights the development of the EMS field and illustrates the historical "instability" (p. 44) of it (e.g., the "distinct boundary between EMS and other medical specialties that it interfaces with daily, including emergency medicine" ( $p$. 44)), the stories offered help "preserve medical practices and tactics that newer EMS professionals might not learn in the classroom" (p. 52).

TPC and RHM readers, on the other hand, may be drawn to the book's main goal - to document and discuss EMS communication practices and the rhetorical work involved in such practices - as well as in Angeli's illustrations of how rhetoric has the ability to persuade in the EMS environment through "unquantifiable methods, such as the 
senses, memory, and invention techniques" (p. 14). It is this latter offering that expands understandings about the role and importance of these methods in EMS work and how they play an essential part in how EMS communicators manage the situations they face.

RHM scholars may also be interested in the conversation recognizing the ethical and methodological challenges characteristic of feminist research in Angeli's text. Such challenges include conducting Internet research, working with vulnerable populations, and studying the unpredictable workplace, as Angeli has done. For example, in what Kristin M. Bivens (2018) would describe as a "methodological reflection" (p. 139), Angeli recounts how issues of access and trust impacted her study and how she had to modify a research method, the critical decision method model, to respond to these challenges. Through documentation of her "process-focused" (Walton, Zraly, \& Mugengana, 2015, p. 46) reflection, Angeli both illuminates the "messiness" that often characterizes RHM work (Scott \& Melonçon, 2018, p. 4) and illustrates how RHM scholars deploying feminist methods must often negotiate and adapt their research methods. It is Angeli's reflection that assists in moving the field of RHM forward, for it makes transparent how she responded to the constraints and exigencies found in the unpredictable environment she studied - insights which can help direct other scholars undertaking feminist research in RHM.

Finally, chapter seven may be most useful for TPC, RHM, and EMS educators interested in preparing students and trainees for communicating in the unpredictable workplace. Expertly organized, readers of the chapter are likely to appreciate Angeli's summary of the writing-EMS training disconnect, synthesis of her research findings, and explanations for why pedagogical activities are needed to "account for the rhetorical 
work that is required in the field" (p. 155). Additionally, readers may find value in the amount of contextualization offered by Angeli to understand the purpose for each writing exercise and how each activity can assist students with cultivating particular communication skills. Lastly, readers may appreciate both the scaffolding of each writing assignment and the detailing of how each pedagogical assignment promotes rhetorical work. Overall, Rhetorical Work in Emergency Medical Services is a text that should occupy the bookshelves of those interested in the power of rhetoric and how it presides during emergency medical situations.

\section{References}

Bivens, Kristin M. (2018). Rhetorically listening for microwithdrawals of consent in research practice. In Lisa Melonçon and J. Blake Scott (Eds.), Methodologies for the rhetoric of health \& medicine (pp. 138-156). New York, NY: Routledge.

Scott, J. Blake, \& Melonçon, Lisa. (2018). Manifesting methodologies for the rhetoric of health \& medicine. In Lisa Melonçon and J. Blake Scott (Eds.), Methodologies for the rhetoric of health \& medicine (pp. 1-23). New York, NY: Routledge.

Walton, Rebecca, Zraly, Maggie, \& Mugengana, Jean Pierre. (2015). Values and validity: Navigating messiness in a community-based research project in Rwanda. Technical Communication Quarterly, 24(1), 45-69. 
Marissa C. McKinley, $\mathrm{PhD}$, is an Assistant Teaching Professor of English at Quinnipiac University. At Quinnipiac, Marissa teaches First-Year Writing (FYW) and assists with administering the FYW Program. Her scholarship has most recently been published in the co-edited collection Women's Health Advocacy: Rhetorical Ingenuity for the $21^{\text {st }}$ Century. 